\title{
POTENSI PENYERAPAN KARBON PADA SISTEM AGROFORESTRI DI DESA PESAWARAN INDAH KECAMATAN PADANG CERMIN KABUPATEN PESA WARAN PROVINSI LAMPUNG
}

\section{(THE POTENTIAL CARBON ABSORPTION OF AGROFORESTRY SYSTEMS AT PESAWARAN INDAH VILLAGE PADANG CERMIN SUB DISTRIC PESAWARAN DISTRIC PROVINCE OF LAMPUNG)}

\author{
Dessy Natalia, Slamet Budi Yuwono, dan Rommy Qurniati \\ Kehutanan, Fakultas Pertanian, Universitas Lampung \\ J1. Prof. Dr. Sumantri Brojonegoro No.1 Bandar Lampung, 35145 \\ dessysiburian@ymail.com
}

\begin{abstract}
ABSTRAK
Penelitian bertujuan untuk mengetahui vegetasi dominan dan besarnya serapan karbon dari sistem agroforestri. Penelitian dilaksanakan di Desa Pesawaran Indah Kecamatan Padang Cermin Kabupaten Pesawaran Provinsi Lampung. Waktu penelitian dilakukan pada bulan April-Juni 2012. Untuk mengetahui vegetasi dominan digunakan metode Summed Dominance Ratio (SDR) dan Indeks Nilai Penting (INP) vegetasi serta untuk menghitung jumlah serapan karbon digunakan persamaan allometrik. Lahan agroforestri terletak pada setiap kategori fisiografi, untuk mempermudah dalam memperoleh data maka Desa Pesawaran Indah dibagi menjadi fisiografi bawah, tengah, atas dan hutan dusun. Vegetasi dominan pada fisografi bawah untuk fase pohon adalah Jati (Tectona grandis), untuk fase tiang, pancang dan semai adalah Kakao (Theobroma cacao). Vegetasi dominan fisiografi tengah untuk fase pohon adalah Alpukat (Persea americana), untuk fase tiang, pancang dan semai adalah Kakao (Theobroma cacao). Vegetasi dominan fisiografi atas untuk fase pohon adalah Waru gunung (Hibiscus macrophyllus), untuk fase tiang, pancang dan semai adalah Kakao (Theobroma cacao). Vegetasi dominan hutan dusun untuk fase pohon adalah Tabu (Crescentia pujeta), fase tiang adalah Cempaka (Michelia champaca), fase pancang adalah Bambu (Gigantochloa apus), dan fase semai adalah Karet (Hevea brasiliensis). Serapan karbon di atas permukaan tanah pada sistem penggunaan lahan agroforestri di Desa Pesawaran Indah fisiografi bawah yaitu $118,96 \mathrm{Mg} / \mathrm{ha}$, fisiografi tengah yaitu 104,16 Mg/ha, fisiografi atas yaitu $89,01 \mathrm{Mg} / \mathrm{ha}$ dan pada hutan dusun yaitu $526,43 \mathrm{Mg} / \mathrm{ha}$.
\end{abstract}

Kata kunci : agroforestri, karbon, vegetasi dominan

\section{ABSTRACT}

This research aims to determine dominant vegetation and amount of carbon absorption of agroforestry systems. This research held at Pesawaran Indah Village, Padang Cermin Sub Distric, Pesawaran Distic, Lampung Province on April - June 2012. It is used Summed Dominance Ratio (SDR) methode, vegetation of INP ("Indeks Nilai Penting") and than to calculate the carbon absorption by allometrik equation. Agroforestry land lies on fisiography category. There are three fisiography to ease in obtaining the data. There are low land, middle land, up land and forest hamlet. On low land the dominanat vegetation for tree phase is Teak (Tectona grandis), and for pole, sapling and seedling phase is dominant Cacao (Theobroma cacao). On middle land the dominanat vegetation for tree phase is Avocado (Persea americana), the pole, sapling and seedling phase is dominant Cacao (Theobroma cacao). On up land the dominant vegetation for tree phase is Waru (Hibiscus macrophyllus), 
the pole, sapling and seedling phase is dominant Cacao (Theobroma cacao). On village forest the dominant vegetation for tree phase is Taboos (Crescentia pujeta), pole phase is Champaca (Michelia champaca), sapling phase is Bamboo (Gigantochloa apus) and seedling phase is hevea (Hevea brasiliensis). The results of carbon above absorption on agroforestry lands at Pesawaran Indah Village is 118,96 Mg/ha (low land), 104,16 Mg/ha (Middle land) and 89,01 Mg/ha (up land) and 526,43 Mg/ha (forest hamled).

Key words : agroforestry, carbon, dominant vegetation

\section{PENDAHULUAN}

Pemanasan global merupakan perubahan iklim yang disebabkan oleh konsentrasi emisi gas rumah kaca dalam bentuk $\mathrm{CO}_{2}, \mathrm{CH}_{4}$ dan bentuk lainnya yang berlebih di atmosfer. Gas tersebut berasal dari pembakaran bahan bakar fosil, kebakaran hutan, konversi hutan dan aktivitas lain yang menyebabkan semakin berkurangnya penutupan vegetasi (deforestasi dan degradasi) yang selanjutnya menyebabkan penurunan penyerapan karbon.

Menurut Dinas Kehutanan Provinsi Lampung tahun 2010, tingkat kerusakan hutan di Provinsi Lampung yang disebabkan kebakaran, deforestasi dan degradasi sudah mencapai $65,47 \%$. Hal inilah yang mendorong optimalisasi penggunaan lahan dapat segera diupayakan agar luasan hutan tidak semakin berkurang dan hutan mampu melakukan salah satu fungsinya sebagai penyerap karbon. Pengoptimalisasian lahan dapat dilakukan antara lain dengan sistem agroforestri (Hairiah dan Rahayu, 2007).

Masyarakat Desa Pesawaran Indah mengelola lahan dengan sistem tanam agroforestri. Keberadaan vegetasi di Desa Pesawaran Indah dapat menunjukkan seberapa besar karbon dapat diserap dari lingkungan. Alasan dilakukannya penelitian yaitu mendorong peningkatan pengelolaan Sumber Daya Alam (SDA) dalam memaksimalkan fungsi lahan menyerap karbon. Tujuan penelitian ini untuk mengetahui jenis vegetasi dominan dan mengetahui besarnya serapan karbon dari sistem agroforestri Desa Pesawaran Indah. Penelitian ini diharapkan dapat dijadikan sebagai informasi dalam pemilihan jenis vegetasi oleh masyarakat dan pendugaan potensi simpanan karbon dari sistem agroforestri yang ada di Desa Pesawaran Indah, sehingga mendukung upaya pemerintah dalam menekan laju perubahan iklim global.

\section{METODE PENELITIAN}

Penelitian dilaksanakan pada bulan April - Juni 2012 di Desa Pesawaran Indah Kecamatan Padang Cermin Kabupaten Pesawaran. Objek penelitian ini adalah lahan agroforestri, pohon, tiang, pancang, tumbuhan bawah (semai) dan serasah di permukaan tanah dalam petak ukur. Alat yang digunakan adalah pita ukur, tongkat kayu 1,3 m dan $2 \mathrm{~m}$, parang, spidol, christen hypsometer, kantong plastik, oven, timbangan, tali plastik, alat-alat tulis dan lembar pengamatan. Data yang dikumpulkan berupa data vegetasi (jumlah setiap jenis ditemukan dalam petak ukur, diameter pancang, tiang, dan pohon) diperoleh dengan mendata vegetasi di dalam petak ukur lalu dianalisis dengan Indeks Nilai Penting (INP), INP merupakan penjumlahan Kerapatan Relatif (KR), Dominansi Relatif (DR) dan Frekuensi Relatif (FR). Setelah diperoleh INP, untuk menentukan jenis dominan atau paling melimpah/menonjol digunakan metode Summed Dominance Ratio $(\mathrm{SDR})=$ Indeks Nilai Penting (INP)/3 (Indriyanto, 2006).

Data biomassa (nama jenis pohon, tinggi, diameter, dan berat kering dan basah serasah). Nama jenis pohon, tinggi, dan diameter diperoleh dengan cara pengukuran dan dianalisis dengan persamaan alometrik. Berat kering dan basah serasah diperoleh dengan cara memotong batang dan daunnya, sekitar 100-300 g ditimbang untuk memperoleh berat basah 
lalu dikeringkan di oven dengan suhu $80^{\circ} \mathrm{C}$ selama 48 jam untuk mendapatkan berat kering. Biomassa serasah dianalisis dengan rumus Biomass Expansion Factor (BEF) (Brown, 1997). Data lain untuk mendukung penelitian yaitu keadaan umum lokasi penelitian dan monografi desa.

Pengumpulan data dilakukan dengan membuat 1 petak ukur pada hutan dusun dan 10 petak ukur pada kebun campuran. Pembuatan petak ukur di Desa Pesawaran Indah terbagi menjadi 3 bagian fisiografi lahan yaitu bawah, tengah dan atas. Petak ukur di lapangan, digunakan untuk memperoleh data biomassa dan vegetasi dengan cakupan fase vegetasi, yaitu: petak ukur $20 \mathrm{~m}$ x $20 \mathrm{~m}$ untuk fase pohon (diameter pohon $>20 \mathrm{~cm}$ ), petak ukur $10 \mathrm{x}$ $10 \mathrm{~m}$ fase tiang (diameter pohon 10-20 cm), petak ukur 5 x $5 \mathrm{~m}$ untuk fase pancang (diameter pohon $<10 \mathrm{~cm}$, tinggi $>1,5 \mathrm{~m}$ ), petak ukur $2 \times 2$ untuk fase semai (untuk tinggi tumbuhan < $1,5 \mathrm{~m}$ ), dan petak ukur $0,5 \times 0,5 \mathrm{~m}$ untuk tumbuhan bawah dan serasah.

\section{HASIL DAN PEMBAHASAN}

Penggunaan lahan oleh masyarakat dengan sistem agroforestri di Desa Pesawaran Indah tersebar di setiap fisiografi desa. Dalam mempermudah untuk memperoleh data maka peneliti mengelompokkan lahan agroforestri mulai dari lahan fisiografi bawah (200 mdpl), tengah (400 mdpl), atas (900 mdpl) dan hutan dusun. Berdasarkan pengklasifikasian sistem agroforestri oleh De Foresta (2000), maka setiap fisiografi akan diketahui jenis agroforestri yang digunakan di Desa Pesawaran Indah. Vegetasi penyusun lahan agroforestri terdiri dari tanaman kayu, tanaman Multi Purpose Trees Species (MPTS) dan tanaman pertanian/perkebunan.

Tabel 1. Model persamaan allometrik yang digunakan.

\begin{tabular}{|c|c|c|}
\hline No. & Jenis Tegakan & Persamaan Allometrik (Sumber) \\
\hline 1. & Mahoni* & $\mathrm{BK}=0,902\left(\mathrm{D}^{2} \mathrm{H}\right)^{0,08}$ (Purwanto, 2009) \\
\hline 2 & Sonokeling* & BK $0,745\left(D^{2} H\right)^{0,64}$ (Purwanto, 2009) \\
\hline 3. & Jati* & $\mathrm{BK}=0,015\left(\mathrm{D}^{2} \mathrm{H}\right)^{1,08}($ Purwanto, 2009) \\
\hline 4. & Sengon* & $\mathrm{BK}=0,020\left(\mathrm{D}^{2} \mathrm{H}\right)^{0,93}$ (Purwanto, 2009) \\
\hline 5. & Akasia* & $\mathrm{BK}=0,077\left(\mathrm{D}^{2} \mathrm{H}\right)^{0,90}($ Purwanto, 2009) \\
\hline 6. & Pohon-pohon bercabang** & $\mathrm{BK}=0,11 \rho(\mathrm{D})^{2,62}($ Ketterings, 2001) \\
\hline 7. & Pohon tidak bercabang** & $\mathrm{BK}=\pi \rho \mathrm{D}^{2} \mathrm{H} / 40$ (Hairiah, 2002) \\
\hline 8. & Kopi** & $\mathrm{BK}=0,281(\mathrm{D})^{2,0}($ Arifin 2001$)$ \\
\hline 9. & Pisang** & $\mathrm{BK}=0,030(\mathrm{D})^{2,13}$ (Arifin 2001, Van Noordwijk, 2002) \\
\hline 10. & Bambu** & $\mathrm{BK}=0,131(\mathrm{D})^{2,28}($ Priyadarsini, 2000) \\
\hline
\end{tabular}

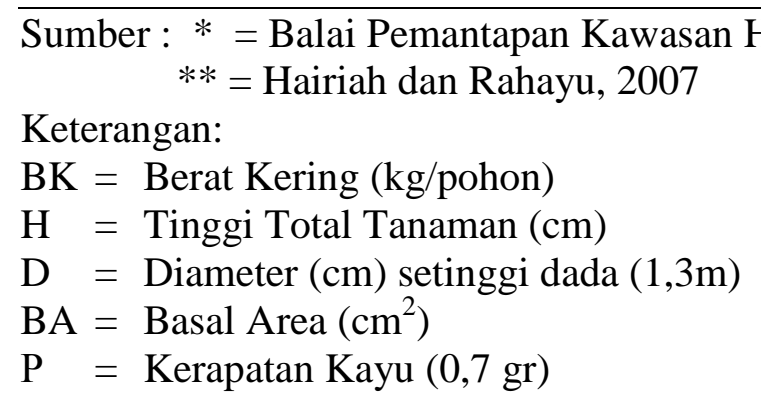


Tabel 2. Rekapitulasi 3 vegetasi dominan pada setiap fisiografi desa.

\begin{tabular}{|c|c|c|c|c|c|c|}
\hline \multirow{2}{*}{\multicolumn{2}{|c|}{$\begin{array}{ll}\text { NO } & \text { Fisiografi Desa } \\
& \text { Pesawaran Indah } \\
\text { 1 } & \text { Fisiografi Bawah }\end{array}$}} & \multicolumn{2}{|l|}{ Fase Pohon } & \multirow{2}{*}{$\begin{array}{l}\text { Fase tiang } \\
\text { Kakao }(152,55)\end{array}$} & \multirow{2}{*}{$\begin{array}{l}\text { Fase pancang } \\
\text { Kakao }(129,86)\end{array}$} & Fase semai \\
\hline & & Jati & $(95,33)$ & & & Kakao $\quad(110,95)$ \\
\hline & & Bayur & $(79,44)$ & $(50,32)$ & Pisang $(105,68)$ & $(35,63)$ \\
\hline & & Kelapa & $(60,73)$ & $(49,68)$ & Durian $\quad(33,45)$ & Cengkeh $(15,00)$ \\
\hline & \multirow[t]{3}{*}{2 Fisiografi tengah } & Alpukat & $(50,77)$ & Kakao $(167,17)$ & Kakao $(210,00)$ & $(106,67)$ \\
\hline & & Durian & $(46,69)$ & Kemiri $\quad(38,94)$ & $(69,24)$ & $(25,00)$ \\
\hline & & Jati & $(34,85)$ & Pisang $\quad(36,68)$ & $(20,76)$ & Kemiri \\
\hline & \multirow[t]{3}{*}{3 FisiografiAtas } & Waru & $(79,50)$ & Kakao $(112,25)$ & $(176,03)$ & $(54,17)$ \\
\hline & & \multicolumn{2}{|c|}{ Julang-jaling $(44,61)$} & $(51,70)$ & $(71,41)$ & $(50,09)$ \\
\hline & & Medang & $(38,20)$ & Pisang $(36,73)$ & $(38,00)$ & $(30,89)$ \\
\hline & \multirow[t]{4}{*}{4 Hutan Dusun } & Tabu & $(86,39)$ & Cempaka $(186,28)$ & $(300,00)$ & $(50,00)$ \\
\hline & & Medang & $(59,61)$ & Kemiri $\quad(113,27)$ & & $(50,00)$ \\
\hline & & Cempaka & $(50,95)$ & & & Cempaka $(50,00)$ \\
\hline & & & & & & $(50,00)$ \\
\hline
\end{tabular}

Komposisi penyusun lahan agroforestri fisiografi bawah yaitu Jati (Tectona grandis), Bayur (Pterospermum javanicum), Kelapa (Cocos nucifera), Kakao (Theobroma cacao), dan Pisang (Musa spp). Jati (Tectona grandis) dengan INP 95,33\% (Tabel 2) merupakan jenis vegetasi dominan pada fase pohon. Jati merupakan jenis dominan karena petani sengaja menanam Jati dalam jumlah banyak (diperkirakan dalam 1 ha dengan jarak 3 x $3 \mathrm{~m}$ terdapat 1.111 pohon) untuk menambah pendapatan. Saat ini pohon Jati yang sudah tumbuh di lahan fisiografi bawah sudah berdiameter 20-30 cm atau berumur sekitar 10-15 tahun menunjukkan bahwa Jati merupakan jenis dominan dengan diameter cukup besar. Jenis vegetasi dominan fase pohon selain jati adalah Bayur (Pterospermum javanicum) dengan INP 79,44\% (Tabel 2). Bayur dimanfaatkan sebagai penaung tanaman dan pembatas lahan. Fase pohon dominan selanjutnya adalah tanaman Kelapa (Cocus nucifera) dengan INP 60,73\%, dan dimanfaatkan sebagai pembatas lahan, serta hasil buahnya dapat dipanen oleh petani.

Vegetasi dominan pada fase tiang adalah Kakao dengan INP 152,55\%, vegetasi dominan pada fase pancang adalah Kakao dengan INP 129,86\% dan vegetasi dominan pada fase semai adalah Kakao dengan INP 110,95\% (Tabel 2). Distribusi jenis tiang, pancang dan semai yang dominan pada saat ini di lahan fisiografi bawah akan menjadi jenis pohon dominan pada skala waktu di masa yang akan datang.

Komposisi penyusun fisiografi tengah adalah tanaman MPTS yaitu Alpukat (Persea americana), Durian (Durio zibethinus), tanaman kayu yaitu Jati (Tectona grandis), tanman pertanian yaitu Pisang (Musa spp), dan Kakao (Theobroma cacao). Alpukat (Persea americana) merupakan jenis fase pohon yang dominan dengan INP sebesar 50,77\% diikuti jenis Durian (Durio zibethinus) 46,69\% (Tabel 2). Berdasarkan nilai INP setiap fase vegetasi lahan fisiografi tengah pada Tabel 2, diketahui bahwa jenis tanaman semusim lebih dominan dari jenis pohon dominan yang ada yaitu jenis tanaman MPTS. Hal ini menunjukkan bahwa petani menanam jenis pohon hanya untuk pembatas lahan dan penaung tanaman. Dalam kenyataannya, fase pohon memiliki peran ekologis lebih tinggi dari tiga fase lainnya yaitu sebagai penyerap karbon terbesar, penyumbang $\mathrm{O}_{2}$ terbesar, dan daya cengkeram akar yang lebih kuat (Hairiah dan Rahayu, 2007). Rahayu (2010) menuliskan bahwa pohon buahbuahan dan kayu berumur panjang mampu menyimpan karbon lebih banyak bila dibandingkan dengan tanaman semusim.

Fase tiang, pancang dan semai pada fisiografi tengah didominasi oleh vegetasi Kakao (Theobroma cacao), Pisang (Musa spp), Kemiri (Aleurites moluccana), Pala (Myristica fragrans) dan Karet (Hevea brasiliensis). Jenis tiang, pancang dan semai dominan 
disebabkan petani membutuhkan vegetasi yang hasil panennya berkesinambungan. Komposisi tanaman penyusun lahan fisiografi atas adalah Waru gunung (Hibiscus macrophyllus), Julang-jaling (Archidendron microcarpum), Medang (Litsea spp), Kakao (Theobroma cacao), Pisang (Musa spp) dan Kopi (Coffea arabica L). Lahan fisiografi atas juga termasuk dalam agroforestri kompleks. Waru gunung dengan INP 79,50\% (Tabel 2) adalah jenis vegetasi fase pohon yang dominan di fisiografi atas dan dimanfaatkan untuk penaung tanaman dibawahnya serta untuk menahan erosi karena berada pada fisiografi lahan atas. Menurut Rachman (2000), jenis waru gunung (Hibiscus macrophyllus) cocok ditanam di dataran tinggi dan termasuk jenis pengendali erosi karena memiliki akar tunjang yang panjang. Vegetasi Julang-jaling (Archidendron microcarpum) dengan INP 44,61\% dan Medang (Litsea spp) INP 38,20\% (Tabel 2) merupakan jenis dominan selanjutnya yang dimanfaatkan sebagai pembatas lahan dan penaung tanaman dibawahnya yaitu Kakao (Theobroma cacao), Pisang (Musa spp) dan Kopi (Coffea arabica L). Tanaman Kakao, Pisang dan Kopi juga termasuk dalam jenis dominan pada fase tiang, pancang dan semai.

Hutan dusun merupakan hutan yang sangat dijaga keberadaannya, dibuktikan dengan adanya larangan dari Kepala Desa tidak diperbolehkan adanya pemanenan kayu di hutan dusun. Komposisi tanaman di hutan dusun terdiri dari jenis kayu keras seperti Tabu (Crescentia pujeta), Cempaka (Michelia champaca), Medang (Litsea spp), Bambu (Gigantochloa apus), Karet (Hevea brasiliensis), Palem (Chrysalidocarpus) dan termasuk dalam sistem agroforestri kompleks. Jenis pohon Tabu dominan di hutan dusun dilihat dari INP 86,39\% (Tabel 2). Diameter pohon Tabu $>30 \mathrm{~cm}$ dan tinggi pohon yang menjulang menunjukkan bahwa tegakan vegetasi tabu pada hutan dusun mampu atau menang berkompetisi dalam perebutan akan zat hara, sinar matahari dan ruang tumbuh. Heddy dan Kurniati (1996) dalam Situmorang (2010) menuliskan bahwa umumnya jenis yang dominan dalam suatu komunitas mempunyai peranan yang penting yaitu sebagai indikator kesesuaian habitat dengan jenis vegetasi di dalamnya.

Jenis Cempaka (Michelia champaca) dan Kemiri (Aleurites moluccana) berdasarkan hasil inventarisasi di hutan dusun termasuk dalam fase tiang, jenis ini tumbuh melalui regenerasi alami yaitu tumbuh dengan alami karena biji jatuh ke tanah dan tumbuh sebagai anakan baru. Selain fase tiang, hutan dusun juga disusun oleh fase pancang yaitu jenis Bambu (Gigantochloa apus) yang berpotensi menjaga mata air dibawahnya. Menurut Purwati (2011) bambu memiliki perakaran yang cukup baik dalam menyimpan air. Jenis semai dominan di hutan dusun adalah Karet (Hevea brasiliensis), Palem (Chrysalidocarpus), Cempaka (Michelia champaca), dan Tabu (Crescentia pujeta) dengan rata-rata INP 50,00\% (Tabel 2).

Nilai serapan karbon menunjukkan jumlah karbon/gas rumah kaca di udara yang mampu diserap vegetasi melalui proses fotosintesis (Rahayu, dkk 2004). Perhitungan serapan karbon dilakukan dengan tidak memanen, artinya nilai yang dihasilkan merupakan dugaan potensi.

Lahan agroforestri fisiografi bawah berpotensi menyerap karbon 118,96 Mg/ha, lahan agroforestri fisiografi tengah berpotensi menyerap $104,16 \mathrm{Mg} / \mathrm{ha}$, lahan agroforestri fisiografi atas berpotensi menyerap $89,01 \mathrm{Mg} / \mathrm{ha}$ dan hutan dusun berpotensi menyerap $526,43 \mathrm{Mg} / \mathrm{ha}$ (Tabel 3). 
Berdasarkan hasil penyerapan karbon dari setiap fisiografi tersebut, maka dapat diketahui kemampuan serapan karbon pada sistem agroforestri di Desa Pesawaran Indah yaitu 209,64 Mg/ha (angka diperoleh dari akumulasi rata-rata penyerapan setiap fisiografi dan hutan dusun) dan tergolong baik. Menurut Intergovermental Panel on Climate Change (IPCC, 2007), angka stok karbon yang direkomendasikan pada kategori lahan hutan primer, agroforestri dan sekunder (forest land) adalah $138 \mathrm{Mg} / \mathrm{ha}$ tergolong baik dan jika hasil serapan karbon dibawah dari $138 \mathrm{Mg} / \mathrm{ha}$ maka stok karbon dikatakan kurang baik.

Untuk saat ini, kemampuan serapan karbon dari lahan agroforestri Desa Pesawaran Indah dapat dijadikan informasi bagi pemerintah Provinsi Lampung dalam membantu pencapaian target menurunkan emisi GRK sebesar 26\% dalam 20 tahun (Bappeda, 2012), diasumsikan per tahunnya menurunkan emisi 2,6\% dan dari kehutanan ditargetkan menurunkan 2,78\%. Berdasarkan data Badan Pusat Statistika Lampung (2010) luas hutan Provinsi Lampung adalah 3.742.327 ha, dan keadaan hutan yang belum rusak adalah 34,53\%. Desa Pesawaran Indah termasuk dalam skala hutan 0,054\% berdasarkan luas hutannya. Hasil serapan karbon Desa Pesawaran Indah 209,64 Mg/ha mampu menyumbang 0,000356061\% untuk target Provinsi Lampung menurunkan 2,78\% emisi GRK dari bidang kehutanan.

Selain membantu memberi informasi bagi pemerintah, berdasarkan kemampuan vegetasi, dan keanekaragamannya di lahan agroforestri Desa Pesawaran Indah, maka penelitian ini dapat diklasifikasikan sebagai upaya adaptasi perubahan iklim. Diklasifikasikan sebagai prilaku adaptasi karena menurut Malmsheimer, dkk (2008) dalam Tigor (2009) menuliskan bahwa adaptasi perubahan iklim adalah strategi menciptakan hutan dengan kondisi yang lebih sehat dan mampu memberikan manfaat dalam mengurangi dampak perubahan iklim.

Perbedaan jumlah serapan karbon pada setiap fisiografi lahan tentunya dipengaruhi oleh keragaman vegetasi, dominansi (INP) komposisi fase vegetasi, diameter jenis vegetasi, dan jenis tanahnya serta cara pengelolaan lahan (Rahayu, dkk, 2007). Data primer dari hasil perhitungan juga menunjukkan bahwa setiap fase vegetasi menyimpan biomassa berbedabeda. Hasil hitungan tersebut disajikan pada Tabel 3.

Tabel 3. Jumlah serapan karbon di Desa Pesawaran Indah.

\begin{tabular}{|c|c|c|c|c|c|c|c|}
\hline \multirow[b]{2}{*}{ No. } & \multirow[b]{2}{*}{ Lokasi } & \multicolumn{5}{|c|}{ BIOMASSA } & \multirow{2}{*}{$\begin{array}{c}\text { Serapan }(\mathrm{Mg} / \mathrm{Ha}) \\
\text { Karbon } \\
(\text { Total x } 50 \% \\
\end{array}$} \\
\hline & & $\begin{array}{l}\text { Fase } \\
\text { Pohon }\end{array}$ & $\begin{array}{l}\text { Fase } \\
\text { Tiang }\end{array}$ & $\begin{array}{c}\text { Fase } \\
\text { Pancang }\end{array}$ & $\begin{array}{c}\text { Tumbuhan } \\
\text { Bawah }\end{array}$ & Total & \\
\hline & 1 Fisiografi Bawah & 171,71 & 41,84 & 15,24 & 9,12 & 237,91 & 118,96 \\
\hline & 2 Fisiografi Tengah & 152,26 & 31,66 & 13,70 & 10,70 & 208,32 & 104,16 \\
\hline & 3 Fisiografi Atas & 102,37 & 43,27 & 20,36 & 12,02 & 178,02 & 89,01 \\
\hline & 4 Hutan Dusun & 1022,32 & 16,05 & 6,26 & 8,22 & 1052,86 & 526,43 \\
\hline & Jumlah & 1448,66 & 132,82 & 55,56 & 40,06 & 1677,11 & 838,55 \\
\hline & Rata-rata & 362,17 & 33,21 & 13,89 & 10,01 & 419,28 & 209,64 \\
\hline & Perseentase & 86,38 & 7,92 & 3,31 & 2,39 & & \\
\hline
\end{tabular}


Tabel 4. Rekapitulasi serapan karbon pada 3 vegetasi dominan di setiap fisiografi desa.

\begin{tabular}{ccccccc}
\hline No & Fisiografi Desa Pesawaran Indah & \multicolumn{5}{c}{ INP $(\%)$} \\
\hline & Fase Pohon & \multicolumn{2}{c}{ Fase Tiang } & \multicolumn{2}{c}{ Fase Pancang } \\
\hline & Jati & $(69,87)$ & Kakao & $(10,56)$ & Kakao & $(14,03)$ \\
\hline 1 Fisiografi bawah & Bayur & $(41,83)$ & Pala & $(6,50)$ & Pisang & $(1,22)$ \\
\hline & Kelapa & $(18,98)$ & Bayur & $(9,79)$ & Durian & $(3,43)$ \\
\hline & Alpukat & $(21,11)$ & Kakao & $(4,18)$ & Kakao & $(8,92)$ \\
\hline & Durian & $(53,92)$ & Kemiri & $(10,70)$ & Pisang & $(0,67)$ \\
\hline & Jati & $(7,52)$ & Pisang & $(2,17)$ & Pala & $(2,17)$ \\
\hline & Waru & $(25,87)$ & Kakao & $(3,01)$ & Kakao & $(4,71)$ \\
\hline & Julang-jaling $(15,62)$ & Waru & $(15,37)$ & Kopi & $(10,35)$ \\
\hline 3 Fisiografi atas & Medang & $(12,93)$ & Pisang & $(0,75)$ & Pisang & $(0,81)$ \\
\hline & Tabu & $(392,38)$ & Cempaka $(32,83)$ & Bambu & $(6,26)$ \\
\hline & Medang & $(201,56)$ & Kemiri & $(9,80)$ & & \\
\hline 4 Hutan dusun & Cempaka & $(194,51)$ & & & & \\
\hline
\end{tabular}

Berdasarkan Tabel 2 dan Tabel 4, dapat dilihat bahwa nilai INP suatu vegetasi tinggi akan menyimpan biomassa yang tinggi jika diameternya besar, namun apabila INP tinggi tetapi diameternya kecil biomassanya akan lebih rendah. Hal ini dibuktikan pada jenis Pala dan Bayur yang ada di lokasi penelitian. Pala pada fase tiang di fisiografi bawah memiliki INP sebesar 50,32\% (Tabel 2) menyimpan biomassa 6,50 Mg/ha (Tabel 4) sedangkan Bayur dengan INP sebesar 49,68\% (Tabel 2) mampu menyimpan biomassa lebih banyak dari Pala yaitu $9,79 \mathrm{Mg} / \mathrm{ha}$ (Tabel 4).

Semakin besar diameter pohon penyusun suatu tegakan dengan jumlah individu yang dominan dan disusun oleh jenis-jenis yang mempunyai kerapatan kayu tinggi maka potensi biomasa dan kandungan karbonnya juga semakin besar (Wahyu, dkk, 2010). Hasil penelitian ini mengindikasikan bahwa biomassa pada suatu tegakan tidak hanya dipengaruhi oleh salah satu parameter saja, tetapi parameter yang disebutkan Wahyu, dkk (2010) akan secara bersama-sama memberikan kontribusi dalam besarnya nilai cadangan karbon suatu tegakan.

Lahan fisiografi bawah menyerap karbon dalam kategori kurang baik. Hal ini disebabkan petani pemilik lahan melakukan pengelolaan dengan meregenerasi tanaman kakao (tanaman dominan di fase tiang, pancang, dan semai) yang sudah tidak produktif dengan menebangnya. Kegiatan penebangan tentunya akan berpengaruh terhadap kemampuan fungsi lahan dalam menyerap karbon karena menurut Lasco (2002) menuliskan bahwa aktivitas penebangan hutan untuk pemanenan kayu berperan dalam menurunkan cadangan karbon di atas permukaan tanah minimal 50\%. Selain menebang Kakao, petani pemilik pohon Jati pada fisiografi bawah berencana menebang Jati untuk dua tahun kedepan dengan memanen berdasarkan kebutuhan. Diperkirakan lahan dengan 1 ha kurang lebih terdapat 1.111 pohon Jati yang akan dipanen agar serapan karbon dapat dipertahankan, maka di lahan fisiografi bawah perlu perencanaan yang baik dalam kuantitas memanen Jati dan perlu banyak menanam jenis kayu berdiameter besar lainnya. 
Lahan fisiografi tengah memiliki kemampuan menyerap karbon 104,160 Mg/ha lebih kecil dibanding fisiografi bawah yaitu $118,96 \mathrm{Mg} / \mathrm{ha}$ (Tabel 3). Hal ini dikarenakan pada lahan fisiografi tengah, tanaman semusim pada fase tiang, pancang dan semai memiliki diameter cukup besar dan INP lebih tinggi dari tanaman kayu dan tanaman MPTS yang termasuk dalam fase pohon. Jika INP tanaman MPTS tinggi dan diameternya besar maka mungkin saja biomassa yang disimpan pada fase pohon akan lebih besar karena menurut Rahayu, dkk (2010) pohon buah-buahan dan kayu berdiameter besar mampu menyimpan karbon lebih banyak bila dibandingkan dengan tanaman semusim.

Lahan fisiografi atas disusun oleh komposisi vegetasi seperti Waru gunung (Hibiscus macrophyllus), Julang-jaling (Archidendron microcarpum), dan Medang (Litsea spp) dikombinasikan dengan Kakao-Kopi menghasilkan serapan karbon 89,01 Mg/ha lebih tinggi jika dibandingkan dengan hasil penelitian Murdiyarso, dkk, (2002) yang menunjukkan bahwa rata-rata penyimpanan $\mathrm{C}$ pada sistem agroforestri berbasis kopi adalah $82 \mathrm{Mg} / \mathrm{Ha}$. Kondisi ini dikarenakan jenis tanaman kayu pada fase pohon berdiameter besar dan memiliki INP yang cukup tinggi dijadikan pohon pelindung tanaman Kakao-Kopi.

Di dalam hutan dusun ditemukan pohon berdiameter $>50 \mathrm{~cm}$. Keberadaan pohon yang berdiameter $>30 \mathrm{~cm}$ pada suatu sistem penggunaan lahan, memberikan sumbangan yang cukup berarti terhadap total cadangan karbon. Pada hutan primer $70 \%$ dari total biomasa berasal dari pohon yang berdiameter $>30 \mathrm{~cm}$, sedangkan pohon yang berdiameter antara 5-30 $\mathrm{cm}$ hanya sekitar 30\% (Rahayu, dkk, 2004).

Mencermati data hasil penelitian dan pengamatan dari setiap fisiografi lahan, dapat disimpulkan bahwa hutan dusun memiliki kapasitas serapan karbon yang jauh lebih besar dibanding dengan kebun campuran. Hal ini disebabkan oleh kerapatan pohon/vegetasi lahan hutan dusun sangat tinggi. Hairiah dan Rahayu (2007) mengatakan, tanaman atau pohon berumur panjang yang tumbuh di hutan maupun di kebun campuran (agroforestri) merupakan tempat penimbunan atau penyimpanan $\mathrm{C}(\operatorname{rosot} \mathrm{C}=\mathrm{C} \operatorname{sink})$ yang jauh lebih besar daripada tanaman semusim.

\section{SIMPULAN}

Jenis vegetasi dominan di Desa Pesawaran Indah pada fisiografi bawah adalah Jati (Tectona grandis) dengan nilai INP 95,33\%, Kakao (Theobroma cacao) INP 129,89\% dan Bayur (Pterospermum javanicum) INP 79,44\%. Vegetasi dominan fisiografi tengah adalah Alpukat (Persea americana) dengan nilai INP 50,77\%, Pisang (Musa spp) INP 69,24\% dan Kakao (Theobroma cacao) INP 210\%. Vegetasi dominan fisiografi atas adalah Waru gunung (Hibiscus macrophyllus) dengan nilai INP 79,50\%, Kopi (Coffea arabica L) INP 71,41\%, Julang-jaling (Archidendron microcarpum) INP 44,61\%, dan Kakao (Theobroma cacao) INP 176,03\%. Vegetasi dominan hutan dusun adalah Tabu (Crescentia pujeta) dengan nilai INP 86,03\%, Medang (Litsea spp) INP 59,61\% dan Cempaka (Michelia champaca) INP 50,95\%.

Lahan agroforestri fisiografi bawah berpotensi menyerap karbon 118,96 Mg/ha, lahan agroforestri fisiografi tengah 104,16 Mg/ha, lahan agroforestri fisiografi atas $89,01 \mathrm{Mg} / \mathrm{ha}$ dan hutan dusun 526,43 Mg/ha. Rata-rata serapan karbon pada sistem agroforestri di Desa Pesawaran Indah yaitu 209,64 Mg/ha termasuk kategori baik.

\section{DAFTAR PUSTAKA}

Balai Pemantapan Kawasan Hutan XI. 2009. Potensi Kayu dan Karbon Hutan Rakyat di Pulau Jawa Tahun 1990-2008.

Bappeda. 2012. Penyusunan Rencana Aksi Daerah penurunan emisi Gas Rumah Kaca (RADGRK). Badan Perencanaan Pembangunan Daerah (Bappeda). Lampung. 
BPS. 2010. Lampung Dalam Angka. Badan Pusat Statistik. Lampung.

Brown, S. 1997. Estimating Biomass and Biomass Change of Tropical Forests, a Primer. FAO Forestry Paper 134. FAO Rome.

De Foresta, H. and G. Michon. 1997. The agroforest alternative to Imperata grasslands: when smallholder agriculture and forestry reach sustainability. Agroforestry-Systems. Diakses Tanggal 20 Desember 2012. Pukul 17.00 WIB.

Sumber www.worldagroforestry.org/sea/afmodels/LectureNote1. pdf. (36):105-120p.

Hairiah, K., Subekti, R. 2007. Pengukuran karbon tersimpan di berbagai macam penggunaan lahan. World Agroforestry Centre ICRAF. Bogor.

IPCC (Intergovernmental Panel on Climate Change). 2007. Contribution of Working Group III to the Fourth Assessment Report of the Intergovernmental Panel on Climate Change. B. Metz, O.R. Davidson, P.R. Bosch, R. Dave, L.A. Meyer (eds). Cambridge University Press, Cambridge, United Kingdom and New York, NY, USA.

Indriyanto. 2006. Ekologi Hutan. Buku. PT. Bumi Aksara. Jakarta.

Lasco, R. D. 2002. Forest carbon budgets in Southeast Asia following harvesting and land cover change. in: impacts of land use change on the terrestrial carbon cycle in the Asian Pacific Region. Science in China. Vol. 45, 76-86.

Murdiyarso, D., Van Noordwijk, M., Wasrin U. R., Tomich, T. P., and A. N. Gillison. 2002. Environmental benefits and sustainable land-use options in the Jambi transect, Sumatra, Indonesia. Journal of Vegetation Science 13: 429-438.

Purwati, A. 2011. Serumpun Bambu Sejahterakan Masyarakat. Artikel Blog. Diakses tanggal 25 September 2012. http://www. beritabumi.or.id/?g=beritadtl\&newsID=B0365 \&ikey $=1$.

Rachman, E. 2000. Perencanaan penanaman untuk rehabilitasi hutan dan lahan terdegradasi di Jawa Barat. Prosiding. Dialog Stake holder Kegiatan Rehabilitasi Lahan Kritis Berbasis Pemberdayaan Masyarakat Pedesaan di Kabupaten Ciamis. Bandung.

Rahayu, S., Lusiana, B., Noordwijk, M. V. 2004. Pendugaan cadangan karbon di atas permukaan tanah pada berbagai sistem penggunaan lahan di Kabupaten Nunukan, Kalimantan Timur. Kalimantan.

Rahayu, S., Setiawan, E., Suyanto. 2010. Sistem agroforestri di kawasan penyangga hutan lindung Sesaot: potensinya sebagai penambat karbon. World Agroforestry Centre ICRAF.

Situmorang. 2010. http://respository. usu. ac.id/bitstream/123456789/3/chapter\%20III-V.pdf. Diakses Tanggal 18 Juni 2012. Pukul 00.03 WIB.

Tigor. 2009. Inovasi manajemen kehutanan untuk solusi perubahan iklim di Indonesia. Jurnal Jurnal Analisis Kebijakan Kehutanan. Vol. 6 No. 2, Agustus 2009 : 121 - 129.

Wahyu, C., Indrawan, A., Supriyanto., Hadi, S. 2010. Kontribusi sistem agroforestri terhadap cadangan karbon di hulu Das Kali Bekasi. Bekasi. 
Vol. 2 No. I. Januari 2014 (II-20)

Halaman ini sengaja dikosongkan 